\title{
A study on the birth and globalization of sports originated from each continent
}

\author{
Byung Jin Lee', Tae Young Kim², \\ ${ }^{1}$ Suncheon Campus, Polytechnic College (V), Suncheon, Korea \\ ${ }^{2}$ College of Education, Hankuk University of Foreign Studies, Seoul, Korea
}

The purpose of this research is to see how continent specific sports rose to its modern-day status through globalization. This research focuses on the historical background of how England's football, America's national pastime, baseball, Japan's Judo, and Korea's Taekwondo developed into sports in addition to the reasoning behind its globalization. Promoted by England and the rest of the European continent, Soccer is considered to be one of the world's most popular sports and has served its function as a form of cultural imperialism. It has also advanced alongside commerce, missionary work and other types of cultural clashes. In America, baseball was used to integrate its multicultural so- ciety and developed so that the team captain leads the rest of his team. The sports of Oriental countries were reborn through modernization that was influenced by the modern rationality, education etc. of its Western counterparts. Judo and Taekwondo were introduced globally through the Olympic Games. As mentioned above the birth of sporting events has a close connection to a nation's cultural background and globalization has taken different forms depending on which continent it originated from.

Keywords: Globalization of sports, Soccer, Baseball, Judo, Taekwondo

\section{INTRODUCTION}

Historically, all races have their own playing cultures. Physical activities such as running across the fields, throwing objects or stones, shooting arrows, or swimming against the streams, were closely related to human survival and production of resources, all of which are commonly seen in all human histories. As the instinct for play would be a basic human characteristic, the sports, activities requiring physical competition, would be the product of human culture. From this standpoint, sports can be regarded as a cultural byproduct of the integrated human society (Donnelly, 1996).

The various physical cultures which have been organized since the 19th century gradually appeared as means for education and leisure activities, and the ways shown by the historical transition of physical cultures like sports such as gymnastics have evolved in various ways according to the national or ethnic characteristics and geographic environments (Ha, 2006).

There are numerous kinds of sports beloved by people in the world; however, based on sports included in the Olympic Games, they can be classified into three categories: those originated from and organized in England and the European continent; those originated from the Americas, especially the ones developed in the United States and globalized later; and finally, those originated from Asian countries which would actually be the rebirth of traditional physical culture (martial arts) that are modernized to keep up with the cultural changes and requirements in sports.

Based on these traditional physical activities, the football, rugby, hockey, boxing, golf, tennis, horse riding, athletics, badminton, gymnastics, fencing, and archery etc. had been modernized in England and the European countries and propagated to other continents; on the other hand, the sports originated from the American continent such as baseball, basketball, volleyball, and American foot ball were also propagated to other countries. Along with the propagation of these Occidental sports, traditional martial arts such as Judo, Taekwondo, Kendo, Karate, or Wushu, all of which have a long history its country of origin, are also globalized to be

\footnotetext{
${ }^{*}$ Corresponding author: Tae Young Kim (D) http://orcid.org/0000-0001-6519-5249 College of Education, Hankuk University of Foreign Studies, 107 Imun-ro, Dongdaemun-gu, Seoul 02450, Korea

Tel: +82-2-2173-2202, Fax: +82-2-2173-3934, E-mail: ktyoung66@hanmail.net Received: October 1, 2015 / Accepted: December 11, 2015
}

This is an Open Access article distributed under the terms of the Creative Commons Attribution Non-Commercial License (http://creativecommons.org/licenses/by-nc/4.0/) which permits unrestricted non-commercial use, distribution, and reproduction in any medium, provided the original work is properly cited. 
popular sports that anyone can enjoy.

In this study, the socio-cultural background, the globalization, and the intrinsic characteristics of sports and martial arts originated from England and Europe, the Americas, and Asia will be explored from a comparative perspective.

\section{RESULTS AND DISCUSSION}

\section{The characteristic of globalization of the sport originated from England}

How was soccer rooted and nourished in England? Changes and growth of one nation result from the interaction among the traditions, characteristics, or environmental conditions of the country. Similarly, changes and growth of sports culture would also follow this fashion. Since the early 19th century, changes in traditional knowledge which had dominated the thoughts and habits of people in England were decisively influenced by the scientific development rendered by the revolutionary advancement/invention of transportation which facilitated rapid economic growth. Unprecedented developments in human society emerged rapidly along with these dynamic changes that played a big role in modernizing traditional sports and also created and propagated new sports. Among them, soccer and rugby will be reviewed as the following.

A review of the socio-cultural characteristics of ball games organized in England, as the ball games were the plays commonly enjoyed by people in the world, shows that they gradually started to be modernized from traditional group street football games along with the industrial revolution. Especially, soccer and rugby in England have been nourished in private schools called the Public School and the two rival Oxford and Cambridge universities. There, the soccer game was institutionalized as the program to teach and to train middle and high schools and university students staying in dormitories to be the citizen required by the contemporary England society. And from there, the traditional football game was divided into soccer and rugby depending on the combined usage of hands and feet. Being the advanced empire in the early 19th century, England dominated one third of the world; thus, faithful officials and missionaries to be dispatched as a faithful leader to these countries having different cultures and climates were needed to maintain and manage the empire. Accordingly, in the Public Schools and/or in Universities such as Oxford and Cambridge which were established mainly for students from high class exploited the disciplines employed by sports such as traditional football and rugby game which require intensive physical competitions (Kim and Ha, 2012). Upon such physical activities, the code of a gentleman, fair play, amateurism, manner, etc. were introduced to embed the spiritual elements into the sports game which became the symbol of the modern sports training the mind and body. And then, the elite educated from these schools were dispatched to colonies scattered around the world to be the leader or ruler; they would exploit the native sports culture in order to contact with the native people by trying to propagate several sports into the region to establish cultural tie with them.

As for the football, along with the foundation of England Football Association in 1863, the rules of the game were systemized mainly by the schools and universities that discharged the elite who became global merchants or traders and propagated the game to the rest of the world. And then, the propagated games became popular in almost all the countries. The football game actually was not invented in the England private school (Murray, 2008). But the ball games greatly changed between 1840 s to 1860 s to be reborn as the modernized football game in the Public Schools and Universities. The England football game originally played in wide country fields was modified into games playable on hard ground of small streets in cities along with the industrial revolution which began in 1750s. The leisure times determined by the seasons and the feudatory obligations turned into times to be determined by the electrical lights in factories and to be restricted strictly by the employers. Improvements in roads and traffic systems enabled the games to be held outside the communities; in particular, the locomotives that connected the cities in England helped establish the foundation to hold country-wide matches.

People educated from private schools intended to play the football game with others but the rules they had with the football game they had been enjoying were different from those of others; thus, the issue to unify the rules of the football game was eventually raised, and thereafter, the unified rules were prepared. And then, the football game was recognized by the governors of the country who intended to build up the great British Empire as an effective disciplinary means for their people to develop good personalities and leadership over the enjoyable play; thus, the football game was actively encouraged and propagated to the outer world.

Since 1870s, the football has been propagated to European countries through close cultural collisions or racial embroilment. And further, the propagation of football to the outer world was continued, not only by colonists, but also by the elite group trough trading or missionary works. Countries that established commercial, economical, educational, and military relationships with England were the first to accept the modernized football. In Europe, Switzerland, and Denmark accepted the football for the first time, 
and then Belgium, the Netherlands, Scandinavian countries, Germany, and France followed; it was also transmitted in sequence to Uruguay, Argentina, and Brazil; and for African countries, the game was propagated by military personnel (Clayton, 1987).

The Fédération Internationale de Football Association (FIFA) was established in Paris by seven countries led by France except England in 1904. And by the year of 1914, the number of its members increased to 24 countries. The rules of the football game are simple enough to understand and it does not require any specific gears to play; thus, anyone can enjoy so long as a ball is available. And everyone knows that these advantages played a big role in the quick propagation of this game to the world. As the richest country in the world at that time, England had adopted the free trade and dominated the world economy between 1850s to 1914. For instance, among all the exports of the world, the England share was 25\% (except the trading amount with colonies). Furthermore, England was the biggest foreign investor.

Until 1914, the world economy had been dominated by England as much about $42 \%$ of the foreign investment was owned by the England people. And the England people also enjoyed the football game with people of high class in countries they traded with, including the colonies; they transmitted the sportsmanship to them and also established close and intimate relationships with them which consequently contributed to the globalization of this football game (Szymanski and Zimbalist, 2005).

Among the rules of the current football game, the 'off-side' rule would be the most ambiguous one. This rule, which denotes foul play, is also adopted by rugby, hockey, and ice hockey where the players are prohibited to play in front of the ball. Then, why would it be unfair to play in front of the ball? When was this rule made, and who made it for what? By any stretch of our common sense, this rule might be considered as unreasonable or unnatural one.

In the mid 19th century, when the schools or clubs in England adopted the 'off-side' regulating rule, the situations of players crowded in certain areas inside the yard happened frequently during the football game. And in such crowded situations, the ball in play had to be kicked off forward. But in this play, players frequently kicked other players inadvertently instead of the ball in play which eventually made this situation to be called as "indiscriminate kicking match" in the mid 19th century. However, at that time, this kind of indiscriminate action in the crowd was considered as a behavior to express manliness which captured the young people (Baker, 1983). That is, the frequent crowding in the yard of the football game might be triggered by the young's desire to express their manliness (Young, 1969). Therefore, playing away from the crowd was naturally considered not to be manly.

Unfortunately, the exact time, reason, place, and people for the employment and application of the rule of 'off-side' in the history of football are not clear yet. Since its appearance in the history of this game, however, the rule of 'off-side' has been changed several times; but the basic thoughts of the rule remain unchanged and have strictly regulated the football game so far.

Recently, the rules of many sports games have changed for the convenience of the spectators and along with these trends in other sports, there also occurred movements by some people working in the fields related to the football game. They raised the issue of excluding the 'off-side' rule due to its ambiguity in making exact judgment and its attribute which might bring irrational consequences of reducing the interest of the spectators in the game. That is, the assertion that the 'off-side' rule seizes the players who are trying to get more goals in the game and causes the game to lose its attractive features of making goals became quite persuasive. However, the FIFA rejected such request for the revision of the rules by expressing that the 'off-side' rule has been the representative aspect of the football game; therefore, keeping the rule would be inevitable and even crucial as the football itself cannot live without it.

However, football has not only positive aspects but also negative sides which are likely to trigger regional conflicts (Shaw, 1985) and also racial and ethnic strife which sometimes could be intensified to even a signal of civil war between two countries (Croatia and Serbia) (Lalic and Vrcan, 1998). Football has functioned as a source of nationalism and democracy, as it involves much more direct potential and is more liberating and popular than just leftists' exhausting protests to the Multinational Corporations (Evanson, 1982).

Today, this football game became the most popular game in the world as to be regarded as a global social phenomenon; however, the attitudes toward the traditional elements/aspects of the game being changed are different in Europe and America.

\section{The characteristic of globalization of sports originated from America}

The baseball invented in America was the combination of various traditional British sports such as the cricket, the rounders, and the town ball; it employed the bat and ball to play the game. The baseball today was invented in 1845 by Alexander Cartwright who was the leader of the Knickerbocker Base Ball Club in New York. He made the spacing between each bases constant and made the rule for the nine players in the yard and to be struck out of the 
hitter with three strikes judgment (Vecsey, 2006). Since then, the judges have appeared in the baseball game; but at first, they were sitting on the bench near the third base with their hats and in their swallow-tailed coat. The judges did not make judgment on ball or strike or players out; their major role was to mediate/intervene in the debates between the players and the fans. At this club, the rules of the baseball game were stipulated for the first time and they also wore the uniform for the first time. That is, it was Alexander Cartwright who unified the rules of the baseball game which had been applied differently by region until then. With the establishment of the rules of the baseball game, inter club or inter community baseball games became available. In 1850s, the baseball game became popular in Northeastern America and the admission tickets were sold for special games in order to restrict the number of spectators (Szymanski and Zimbalist, 2005). That was the beginning of commercial sales of the admission tickets for spectators who wanted to see the baseball games. And based on this business of collecting admission fees, the baseball game became highly competitive. The distance between the hitter and the pitcher was initially $14.7 \mathrm{~m}$ ( 45 feet) and it was later extended to $18.44 \mathrm{~m}$ (60 feet and 6 inches).

The first modern baseball game recorded in the history of America was the expeditionary game of the Knickerbocker Base Ball Club held in the Elysian Fields of Hoboken, New Jersey on June 19th, 1846. And in 1857, the Knickerbocker Base Ball Club also invented the short stop position in the baseball game. The number of the whole innings in one game was restricted to 9 innings, and the spacing between the home base and the first base was determined to be $27.43 \mathrm{~m}$ (90 feet). In 1858, the NABBP (National Association of Base Ball Players) was organized based on high society classes who adhered to amateurism (Helyar, 1994), and till the end of 1860s, baseball clubs were actively established in cities of the South and even the West. Since then, the baseball game has been called the "National Game" or has been praised with such comments, "...we think the baseball game would be the best way to teach the American way of thinking and ideal way of being to our boys!..." (David, 2005).

The background of the organization and propagation of the baseball game seems to be closely related with 'Americanism.' Population explosion, industrialization, and the economic development which had started to raise the American social consciousness since 1830s gave huge influence on the American sports culture along with the extended leisure time. Betts (1974) insisted that "the industrialization and urbanization were the fundamental factors for the creation of organized sports..." In other words, the hurricane of the Americanism to make America's own colors and cultures by abolishing feudalism and factionalism has struck the American society since the 1830 s.

A society's sports reflects its own image. That is, this strong wind affected the creation of the American sports culture after the mid 19th century. After the Civil War (1861-1865), the baseball game boomed in North American by riding on the stream of the plenty and hope in postwar era. Places, times, and moneys to enjoy sports game became available in abundance as trains ran across the country, factories in operation, and with expanded urbanization (Betts, 1974). Along with this booming, they set out the expeditionary game in England, the home of cricket, for the first time in 1874. The players from America introduced the baseball game to Liverpool, Manchester, London, Sheffield, and Boston. However, the high class in England who were satisfied with their cricket did not respond in favor. After the game, several players from each team were picked up between 1888 to 1889 to conduct the world baseball game tour starting from Honolulu to New Zealand, Australia, Egypt, Rome, Paris, and London; however, it failed to get good reputation (Goldstein, 1989).

The American Society of the Baseball Game carried out the world baseball game tour again in 1913: from Ohio to cities placed in the Mid-West and the South, and via cities placed on the West coast to Seattle in Australia. And then, they visited Japan via the steam ship where they were welcomed greatly. In the game played against the team from Keio University, 7,000 spectators were gathered. Thereafter, they visited Shanghai, Hong Kong, and the Philippines.

For readers' reference, it was the 1870s when the baseball game was introduced to Japan. Since then, the Yokohama Athletics Club consisting of Americans and the Ichiko (Daiichi high school) Club agreed to hold the international baseball game, and in the game held in 1896, the Ichiko Club defeated the Yokohama Athletics Club by 29:4. The next game was held 2 weeks later, and in the game, the Ichiko Club defeated the Yokohama Athletics Club by 32:9 again. News of these results conveyed via newspapers made the Japanese people to be proud of their club. And since these games, the Japanese people have become fond of the baseball game (Vecsey, 2006).

And thereafter, the American Society of the Baseball Game planned to go to Europe again for the next expeditionary baseball game; but, it was interrupted in Paris, and since then, there have been no notable efforts to globalize the baseball game till the 1990s. American Society of Baseball Game is a collection of various ethnic groups and races. And this type of society usually faces 
the issue of securing social cohesion. The horizontal coexistence of various racial or ethnic differences in harmony would be agreeable; however, there always exist tendencies to discriminate groups vertically. Because of these tendencies, the problem of how to organize the people from various ethnic and racial backgrounds into one culture should be solved.

In the 19th century, Americans had tried to separate themselves from the European traditions. They came to America by crossing the huge ocean to find religious or political freedom. Accordingly, the movements to escape from the European colors were also active in the sports. In the American way of thinking, the desire to devise and establish the national culture for the American people distinguished from the England sports ('National Game') clearly existed (Davis, 1912). This was vividly revealed by the American football. The American football, which combined the British soccer and rugby, is the game made by following the most American style. And the basketball was devised in 1892 for the health education of Christians in wintertime. At first, the basketball was devised by James Naismith who was the teacher of physical education in Young Men's Christian Association (YMCA) to promote physical activities for women in winter time (Naismith, 1941). The volleyball was also devised by the YMCA for the same purpose, and the game prepared nets between the two parties in order to prevent injuries caused by physical contacts (Sherrow, 2002).

These American sports have unique characteristics. For the baseball, the role of the pitcher's position is quite important. The weight of the importance of the pitcher's position is remarkable. Sometimes, the sportscasters would say, "the baseball is the pitchers' play", which represents the importance of the pitchers' role in the baseball game. Currently, the total amount of the pitchers' annual salaries far exceed the ones of the hitters' in 'Major League' of America. What on earth does this mean? That is to say, one team would never lose or could end in a tie in the worst case scenario if their pitcher could play well without any decisive faults till the last 9th inning of the game. And for the American football game, there is the most important position called 'quarterback' who controls and leads the whole play. For example, the quarterback has an omnipotent authority to decide, control, and execute all plays of attack, passing, or running in the game which could determine the whole outcome of the game. This position also marks the highest annual salary in the National Football League (NFL). Then how about playing the basketball? What position in the game would play such an important role? The position of 'Center' became quite important in playing modern basketball game; but still, the 'Guard' plays the role of directing, controlling, and/or taking the final cast. So is there also a position similar to the positions discussed above in the volleyball game? Would it be the 'Right' or the 'Left' hitter? It is the position of the 'Setter.' Even though the hitter would be very tall and could jump very high, he would not be able to make any points unless the setter provides him with accurate tossing of the ball in accordance with his jumping timing, height, angle of spiking, etc. The setter usually puts his/her arms on his/her back to give instructions of the play to his/ her players. Signs for plays such as on attacks, on defenses, or on others are given to players in his/her team in advance. Thus, volleyball teams usually search for capable setters. Like this, the sports originated from America typically require or suppose the role of a certain leader who controls plays and leads the members to make the best of the game.

\section{The characteristics of globalization of sports originated from Asia}

Both Korea and Japan were passively integrated into modern globalization by responding to the compulsive requests of the Western civilization to open their doors. Japan accepted Western culture as they opened the door and participated in the new order of globalization led by the Western countries in order to transform their country into a modern state. And they also actively tried to preserve their own tradition as a means to establish autonomous modern state that is able to stand against the political, economical, and cultural invasion of the Western countries. They recognized and insisted on the thoughts of 'hwahonyangjae' ('WakonYosai, Japanese'; Japanese Spirit with Western Technology) to overcome their inferiorities to the Western countries along with consolidating their own cultural tradition to strengthen the spiritual identity of their people. As a part of the works conducted according to such thoughts, traditional martial arts such as the 'Judo' and 'Kendo' were modernized by imitating modern sports received from the Western countries. Kim (1990) mentioned about these instances, "The greatest change occurred in the history of the Japanese martial arts was that the martial arts acquired the modernity by which the martial arts themselves were transformed from the system of techniques (techniques or arts) into a system of 'ism' (the term implying comprehensive meanings of direction, way, method, road, path, principle, truth, reason, skill, method, etc.), which eliminated the violence." That is, the "flexible physical techniques' became the 'Judo' the ism of flexibility, and the 'art of fencing' became the 'Kendo' the ism of Sword.

So, the traditional 'flexible physical techniques' were modernized into 'Judo' along with catch phrases such as 'jeonglyeogseon- 
yong' ('make good use of powers acquired from hard disciplines') or 'jatagongyeong' ('collaborate together for mutual prosperity') which were employed as spiritual principles for the discipline. The modernized 'Judo' was made by Kano Jigoro (1860-1938) who applied the modern rational and scientific thoughts obtained from the new education of Western Europe to current 'Judo' which is devoid of its previous organizational imperviousness and violence. He insisted on the physical, spiritual, and educational significances in training the 'Judo'. And such thoughts were greatly supported by politicians and even by the people who facilitated the modernization of the 'Judo'. That is, the modernization of 'Judo' in Japan was realized by taking the advantage of epochal stream combined with the element that tried to form the modernized Japanese nation by "preserving traditions" with another element that enabled the making of the national symbol supported by political and social renovation (Kim and Hwang, 2011). Therefore, the Japanese martial arts including 'Judo' were all turned into modern sports by contemporary government and bureaucrats based on their attributes as a physical culture symbolizing the Japanese identity. Since then, Kano Jigoro was elected as a member of the International Olympic Committee (IOC) and he made the efforts to globalize the 'Judo.' In 1955, the International Judo Federation (IJF) was founded and in 1956, the 1st World Judo Championships was held in Tokyo; and in 1964, the Judo was selected as one of Olympic sports in the 18th Tokyo Olympic Games.

Meanwhile, the term 'Taekwondo' had not existed in Korea till 1955 (Kim, 1990; Kim, 2012). In September 1954, the 1st President of Korea, Lee, Seung-Man, attended the 4th anniversary of the No. 1 Military Corps of Korea, and he commented when he saw the military exercises demonstration, "Well, that's the 'TaekGyeon'!" Since then, General Choi, Hong-Hi has adopted the term and converted it into 'Taekwondo' to designate the exercise. According to Kim, Yong-Ok, the term 'Taekwondo' was generalized with the "Military Involvement of the South Korean Army in the Vietnam War" (Kim, 1990). To dispatch the military forces to Vietnam, the training of 'Taekwondo' became obligatory, and through the international efforts of the Korean Army, Taekwondo Demonstration Corps and Military Officers were dispatched to the Vietnam War. Taekwondo gradually became generalized both at home and abroad along with quantitative expansion, and finally, the International Taekwondo Federation was found. Since then, people have made a lot of efforts to discriminate the "Taekwondo' from the Japanese 'Karate.' And by the sports diplomacy capability based on technical innovation and political background, the 'Taekwondo' appeared as a demonstrative sport at 1988 Seoul
Olympic Games and was finally adopted as a regular Olympic sports at 2000 Sydney Olympic Games. Currently, 39 millions of people around the world are enjoying the 'Taekwondo' under the Taegeukgi, the national flag of Korea, by communicating through the globalized Korean terms.

Today, Taekwondo and Judo can also be explained by the changes in paradigm of sports diplomacy. In the stream of postcold war and globalization, social environment seeking cultural diversity is changing globally, and rather than "power to make others do what you want" including military force and economic power, i.e., command power or hard power, attractive power or soft power, which includes culture, virtue, institution, and so on, is being more magnified. Globalization of Taekwondo has been achieved by broad and diverse ways, including nongovernmental overseas expansion, dispatch of exhibition teams to other countries, diplomatic efforts through the establishment of international organizations, and development of Taekwondo for the competition. However, because globalization of sports is not a result of unilateral intention of one side that tries disseminating their sports, but a result of complex process of interdependence whether it is intended or not (Maguire, 2004), further discussion about globalization of Taekwondo should not overlook the parts regarding to mutual dependence.

\section{CONCLUSION}

As the champion of 2010 World Cup held in South Africa, the Spanish football teams are currently showing distinguished plays. Among them, Lionel Messi and Cristiano Ronaldo who are well known star players attract many football fans worldwide. However, neither of them can get a goal by playing alone against the 11 counter players in the game. Thus, even the star players need the organized aids from other players who are equally important in playing successful football game. That is, the positions of offense, defense and goal keeper are equally important in this sport. This is the characteristic feature of the 'England sports' which would normally deny the independent excellence in the game and pursue the system of collaboration requiring all participants to bring out their best effort. This collaborative capability of all team members is also the key to playing successful game in sports like baseball, American football, basket ball or volleyball. However, in the sports originated from America, collaborative teamwork is equally important with one specialized position in the game or excellent leadership of one leading player among the divided roles and positions organized for the game. And thus, the division or assign- 
ment of the role of players in American sports is well explained by the rules allowing the designated hitters in the baseball game, the complete changing of defenders or offenders in the American football game, and the 'Libero' players in the volley ball game. The football game originated from England and propagated globally by Europeans became the most popular sports in the world today. They are also enjoyed by women heavily. The 'Cultural Imperialism' was laid behind this propagation that drove the movement of global trading and/or evangelistic expansion which caused culture shocks and cultural collisions.

The land of America over the Atlantic or Pacific Ocean became one independent country in the 19th century. Since almost all the people who served to establish their own independent country were composed of immigrants with various backgrounds, the country initially needed to decolorize different backgrounds in order to build a unified political, social, and cultural community. So, under the leadership of a few selected leaders, the public consisting of people of diverse races and ethnic backgrounds had to be united by breaking down the barriers against unification. That is, the establishment of one certain type of democratic system led by a few talented people and supported by the public was the issue. This kind of socio-cultural context might have influenced the birth of American sports in which one excellent leader would play a major role in controlling or leading other players, and these sports also functioned as a means to tie the American people from different cultures.

One other characteristic feature of these young American sports is that they do not think much about the traditional aspects of their own; thus, they are quite flexible in taking or discarding the rules or regulations of the game. The introduction of the rules for designated hitters in baseball game or libero players in volley ball game reveals this feature. One definitive instance explaining this feature appeared in 1984 when the United States hosted the World Cup. At that time, the US World Cup Organizing Committee requested the FIFA to revise two rules of the game based on their assumption that the soccer game was not popular among Americans compared to the other American sports such as the American football or the baseball game. The two requests were to discard the 'off-side' rule and to divide the game into three parts consisting of $30 \mathrm{~min}$ from the current two parted game consisting of 45 min just like the basketball game. But FIFA rejected the requests resolutely based on their respect for the tradition of the football game which has strictly maintained the 'off-side' rule and the two parted innings of the game.

This instance reveals the phenomena created by the cultural differences between two continents/regions viewing the sport. It is that the American sports can be viewed from the American business stand point so it would be natural to change anything in sports if it fails to attract people's interest or mass media's attention. By looking at the sports originated from England and America, we can also explore the global political phases from the 19th to the early 20th centuries. The power of contemporary British Empire is reflected in the globalization of the football game, but the Americans did not promote their American football or baseball game to be propagated globally. America also did not have many overseas settlements. These consequences were made probably due to the political and cultural differences. By its geographical conditions and populations, the American sports would not demand globalization and rather, they tended to remain in their country filled with economic abundance, and Americans were inclined to operate their system efficiently. That was, the American sports functioned well as business sports.

Many researchers have studied about "Would process of globalization of sport ultimately accomplish global homogeneity by surpassing the borders between conventional social units?" (Donnelly, 1996; Guttman, 1994). Maguire (1999) explained it with two distinctive perspectives; diversity in globalization and unification in cultural imperialism. He insisted that although the process of globalization of sports partially involves cultural assimilation, at the same time it is a complex course of transformation that forms and reconfirms the differences between individuality, cultural tastes and desires, and regional identity. However, some researchers who handle globalization of sports only with the perspectives of Americanization and westernization of sports, and cultural imperialism tend to declare that it is simply Americanization of sports (Jackson, 1994; Maguire, 1993; Mckay and Miller, 1991) or they explain it as cultural imperialism (Guttman, 1991; Guttman, 1994). Inspite of these kinds of debates, the most important thing to know is that in the understanding of globalization, states are not the crucial units that decide global order (Harvey and Houle, 1994). Now the world is being unified into one whole place, on which the process lasts by interdependence between countries, not by one way power of developed ones. Also, Wagner (1990) suggested that exchanges and stream of global sports culture is experiencing not the expansion or the differentiation of uniqueness or differences, but homogeneity, becoming similar to each other.

Globalization typically accompanies diverse collisions and conflicts through which new cultures are created or existing cultures are revised. This rule applies to the globalization of sports culture as well. Especially, the modernization of martial arts of Asia would 
be called as a rebirth driven by the propagation of modern rationality and mission specific characteristics aimed for educational purposes embedded in Occidental sports. The 'Judo' of Japan was modernized to establish and strengthen the Japanese identity against the invasion of the Western powers, and the 'Taekwondo', the modernized martial arts of Korea, was created by the globalization of the Korean culture which followed the route footed by the Japanese. This reveals the interdependence of sports with contemporaneous, political, economical, and cultural influences. And the 'Taekwondo' might be the best case for the globalization of the Korean culture.

\section{CONFLICT OF INTEREST}

No potential conflict of interest relevant to this article was reported.

\section{ACKNOWLEDGMENTS}

This paper was supported by Hankuk University of Foreign Studies Research Fund of 2015.

\section{REFERENCES}

Baker WJ. The state of British sport history. J Sport Hist 1983;10:53-66.

Betts JR. America's sporting heritage, 1850-1950. Reading (MA): Addison-Wesley Pub. Co.; 1974. p. 240-244.

Clayton A. Sport and African soldiers: the military diffusion of western sport thoughout sub-saharan Africa. In: Baker WJ, Mangan JA, editors. Sport in Africa: essays in social history. New York: Africana Pub. Co.; 1987. p. 176-179.

David B. Baseball before we knew it: a search for the roots of the game. Lincoln (NE): University of Nebraska Press; 2005. p. 207-218.

Davis PH. Football, the American intercollegiate game. New York: Charles Scribner's Sons; 1912. p. 38-45.

Donnelly P. The local and the global: globalization in the sociology of sport. J Sport Soc Issue 1996;20:239-257.

Evanson P. Understanding the people: football, film, theater and politics inpresent-day Brazil. South Atl Q 1982;81:399-412.

Goldstein W. Playing for keeps: a history of early baseball. Ithaca: Cornell University Press; 1989. p. 52-55.

Guttman A. Sport diffusion: a response to maguire and americanization commentaries. Sociol Sport J 1991;8:185-190.

Guttman A. Games and empires: modern sports and cultural imperialism. New York: Columbia University Press; 1994.
Ha NG. A comparative study on the development of physical education between modern Britain and America; ideological similarities and differences. Korean J Phys Educ -Humanit Soc Sci 2006;45:1-12.

Harvey J, Houle F. Sport, world economy, global culture, and new social movements. Sociol Sport J 1994;11:337-355.

Helyar J. Lords of the realism: the real history of baseball. New York: Ballantine Books; 1994.

Jackson S. Rearticulating the americanization of culture debate. Sociol Sport J 1994;11:428-446.

Kim JY. The formation of cultural globalization. In: The Korean Association for Cultural Sociology, editor. Cultural sociology. Paju: Sallim Books; 2012. p. 513-544.

Kim PS, Hwang ER. A study on modernization of Japan's Meiji restoration and military arts. Korea J Sports Sci 2011;20:259-269.

Kim SG, Ha NG. Social history of British football: control and domination by social classes. Korean J Hist Phys Educ Sport Dance 2012;17:1-20.

Kim YO. Principles of Taekwondo philosophy. Seoul: Tongnamu Press; 1990.

Lalic D, Vrcan S. From ends to trenches and back: football in the former Yugoslavia. In: Armstrong G, Giulianotti R, editors. Football cultures and identities. Basingstoke (UK): Macmillan; 1998. p. 35-46.

Maguire J. Globalization, sport development, and the media/sport production complex. Sport Sci Rev 1993;2:29-47.

Maguire J. Global sport: Identities, societies, civilizations. Cambridge: Polity Press; 1999.

Maguire J. Challenging the sport-industrial complex: human sciences, advocacy and service. Eur Phys Educ Rev 2004;10:299-322.

McKay J, Miller T. From old boys to men and women of the corporation: the americanization and commodification of Australian sport. Sociol Sport J 1991;8:86-94.

Murray B. The world's game: a history of soccer. Champaign (IL): University of Illinois Press; 2008. p. 30-61.

Naismith J. Basketball: it's origin and development. Lincoln (NE): University of Nebraska Press; 1941;61-86.

Shaw D. The politics of futbol. History today 1985;35:38-42.

Sherrow V. Volleyball. San Diego (CA): Lucent Books Inc.; 2002.

Szymanski S, Zimbalist A. National pastime: how Americans play baseball and the rest of the world plays soccer. Washington, D.C.: Brookings Institution Press; 2005. p. 59-63.

Vecsey G. Baseball: a history of America's favorite game. Champaign (IL): University of Illinois Press; 2006. p. 30-40.

Wagner EA. Sport in Asia and Africa: americanization or mundialization? Sociol Sport J 1990;7:399-402.

Young PM. A history of British football. London: Stanley Paul; 1969. p. 304-306. 